\title{
Is it Necessary to Perform Sentinel Lymph Node Biopsy in Thin Melanoma? A Retrospective Single Center Analysis
}

\author{
A. Kocsis ${ }^{1} \cdot$ L. Karsko ${ }^{2} \cdot$ Zs. Kurgyis ${ }^{1} \cdot$ Zs. Besenyi ${ }^{2} \cdot$ L. Pavics $^{2} \cdot$ E. Dosa-Racz ${ }^{1} \cdot$ E. Kis ${ }^{1} \cdot$ E. Baltas $^{1} \cdot$ H. Ocsai $^{1}$. \\ E. Varga $^{1} \cdot$ B. Bende ${ }^{1} \cdot$ A. Varga ${ }^{1} \cdot$ G. Mohos ${ }^{1} \cdot$ I. Korom ${ }^{1} \cdot$ J. Varga ${ }^{1} \cdot$ L. Kemeny ${ }^{1} \cdot$ I. B. Nemeth ${ }^{1}$ (D) J. Olah ${ }^{1,3}$
}

Received: 3 June 2019 / Accepted: 21 October 2019 / Published online: 2 December 2019

(C) The Author(s) 2019

\begin{abstract}
Sentinel lymph node biopsy (SLNB) is a standard procedure for regional lymph node staging and still has the most important prognostic value for the outcome of patients with thin melanoma. In addition to ulceration, SLNB had to be considered even for a single mitotic figure in thin $(<1 \mathrm{~mm})$ melanoma according to AJCC7th guideline, therefore, a retrospective review was conducted involving 403 pT1 melanoma patients. Among them, 152 patients suffered from pT1b ulcerated or mitotic rate $\geq 1 / \mathrm{mm}^{2}$ melanomas according to the AJCC7th staging system. SLNB was performed in 78 cases, of which nine (11.5\%) showed SLN positivity. From them, interestingly, we found a relatively high positive sentinel rate (6/78-8\%) in the case of thin primary melanomas $<0.8 \mathrm{~mm}$. Moreover, the presence of regression increased the probability of sentinel positivity by 5.796 fold. After reassessing $\mathrm{pT}$ stage based on the new $\mathrm{AJCC} 8^{\text {th }}, 37 \mathrm{pT} 1 \mathrm{~b}$ cases were reordered into pT1a category. There was no significant relation between other characteristics examined (age, gender, Breslow, Clark level, and mitosis index) and sentinel node positivity. Based on our data, we suggest that mitotic rate alone is not a sufficiently powerful predictor of SLN status in thin melanomas. If strict histopathological definition criteria are applied, regression might be an additional adverse feature that aids in identifying T1 patients most likely to be SLN-positive. After reassessing of $\mathrm{pT} 1 \mathrm{~b}$ cases according to AJCC $8^{\text {th }}$ regression proved to be independent prognostic factor on sentinel lymph node positivity. Our results propose that sentinel lymph node biopsy might also be considered at patients with regressive thin $(<0.8 \mathrm{~mm})$ melanomas.
\end{abstract}

Keywords Melanoma $\cdot$ Sentinel lymph node biopsy $\cdot$ Mitotic rate $\cdot$ Regression $\cdot$ Stage

\section{Introduction}

Although accounting for less than 5\% of skin cancers, malignant melanoma is responsible for $80 \%$ of skin cancer-related deaths, and its incidence is increasing worldwide [1]. Because of increased awareness and earlier diagnosis, approximately $80 \%$ of new cases are in situ or early invasive melanomas. The prognosis

I. B. Nemeth

nemethistvanbalazs@gmail.com; nemeth.istvan.balazs@med.uszeged.hu

1 Department of Dermatology and Allergology, University of Szeged, Szeged, Hungary

2 Department of Nuclear Medicine, University of Szeged, Szeged, Hungary

3 Department of Oncology, Faculty of General Medicine, University of Szeged, Szeged, Hungary for these patients is relatively good, with ten-year survival rates of more than $90 \%$ [2-4].

The result of the Multicentre Selective Lymphadenectomy Trial (MSLT-I) has been published, confirming the previous practice of performing sentinel lymph node biopsy (SLNB) in the case of intermediate and thick melanomas [5]. However, some authors already argue with the result or interpretation [6], highlighting some questionable points of the trial and debating the real benefit of the SLNB to ten-year melanoma-specific survival. The predictive role of sentinel lymph node positivity in thin melanoma has been investigated and reported by several authors [7-11]. There is a consensus in the literature that the metastatic involvement of regional lymph nodes is still one of the most important prognostic factors of thick and thin cutaneous melanomas as well, however, the criteria and the indications of thin melanomas for SLNB are inconsistent and the results both contradictory and incoherent [12].

In 2009, the American Joint Committee on Cancer (AJCC) published the $7^{\text {th }}$ edition of the staging system for melanomas 
which relies on thickness, ulceration and mitotic rate in the dermis. According to $\mathrm{AJCC}^{\text {th }}$ recommendation, SLNB should be considered in the case of melanomas $\leq 1 \mathrm{~mm}$ in thickness, with ulceration or with even a single mitotic fig. [4]. The local guidelines for thin melanomas were modified at our department in early 2011 and the $\mathrm{AJCC} 7^{\text {th }}$ adopted, as SLNB was offered not only if ulceration was present but if mitotic rate $\geq 1 / \mathrm{mm}^{2}$ of the tumour area. According to the new $\mathrm{AJCC}^{\text {th }}$ guidelines, dermal mitoses are not considered for pT1b, however, mitotic activity should be noted as independent prognostic factor [13].

In our retrospective study, we aimed to investigate the predictive value of mitotic rate and to analyse further clinicopathologic predictors of positive SLNB by examining the common feature of these metastasizing cases in order to prevent the majority of the $\mathrm{T} 1 \mathrm{~b}$ melanoma patients from undergoing SLNB. Cases were also reassessed according to the AJCC $8^{\text {th }}$ guideline and additional statistical analyses were performed to re-evaluate the prognostic value of the well-known histological parameters considering $\mathrm{AJCC} 8^{\text {th }}$.

\section{Patients and Methods}

The Department of Dermatology and Allergology, University of Szeged, is a regional centre for the management of cutaneous malignancies, being responsible for melanoma care for the 1.5 million inhabitants of southeastern Hungary. A retrospective review was conducted involving patients treated at our department with thin melanomas $(<1 \mathrm{~mm})$ between January 2011 and December 2014 (Ethical approval: MEL-RETRO-001; number: $3521,40 / 2015)$. During these four years, 625 consequtive primary melanomas were diagnosed at our department. Four hundred and three pT1 melanoma patients entered our study; among these cases, 152 patients suffered from p $11 \mathrm{~b}$ ulcerated or mitotic rate $\geq 1 / \mathrm{mm}^{2}$ melanomas according to the $\mathrm{AJCC} 7^{\text {th }}$ staging system. We also planned to evaluate the common and characteristic features of primary melanomas among thin melanoma cases with sentinel node involvement. On the basis of the histopathological results of the primary tumours, a multidisciplinary tumour board approved a therapeutic plan and the choice of SLNB was discussed with patients in all cases. SLNB was offered to most eligible patients with $\mathrm{pT} 1 \mathrm{~b}$ melanomas as part of their surgical management in the absence of clinically evident nodal disease, or known distant metastases. SLNB was not advised if any sign of dissemination was detected in the case of high biological age, severe comorbidities or pregnancy. Some patients had declined surgery. Seventy-eight cases of SLNB were included in the study based on the criteria which are listed below.

\section{Histopathology}

A standardized histopathological examination was performed on samples of primary melanoma, re-excision and sentinel lymph node dissection. Specimens were fixed in $4 \%$ buffered formaldehyde embedded in paraffin, and $4 \mu \mathrm{m}$ sections were placed on silanized slides. In addition to routine haematoxylin eosin staining (Leica ST5020), further immunohistochemistry (Leica Bond Max Autostainer) involved Melan-A (DAKO; mouse clone A103), HMB45 (Biocare; mouse monoclonal), and occasionally S100 (DAKO, rabbit monoclonal) antibodies in a dilution of $1: 300,1: 200$, and 1:2000, respectively. At least three serial sections were prepared from sentinel node specimens.

\section{Surgical Procedure}

Sentinel lymph node biopsy (SLNB) for the staging of melanoma was first described in detail in 1992. We perform combined radiotracer and blue dye mapping as usual. On the day before the surgery, dynamic lymphoscintigraphy is performed with human albumin colloid (Sentiscint; FJC Institute, Budapest, Hungary, Medi-Radiopharma Ltd., Érd, Hungary) labelled with $99 \mathrm{mTc}$ pertechnetate, with $80 \%$ of the particles sized 100 to $600 \mathrm{~nm}$. As part of the double staining, 0.5 to $2.0 \mathrm{ml}$ vital blue dye (BykGulden, Konstanz, Germany) is injected 15-20 min before the incision. During the operation, a handheld gamma probe (CTrak, AEA Technology, Darwin House, Birchwood Park, Warrington and Navigator GPS System; RMD Instruments Corp. Watertown, MA 02472 USA) is used to identify the hot spots. The nodes with significant activity or with vital blue stain are considered sentinel lymph nodes. The radiotracer activity of these nodes is measured ex vivo and compared to the bed from which they were removed. A radioactive lymph node is defined as positive and removed until the background counts are $<10 \%$ of the hottest node removed. If the postoperative histology reveals metastasis in the lymph nodes, completion lymph node dissection is offered to the patient.

\section{Statistical Methods}

The SLN positivity rate was the primary outcome. The clinicopathological features analysed were age, sex, melanoma type, location, ulceration, Breslow thickness, Clark level, mitotic rate, regression, and SLN status. The relationships between SLN positivity and each of the clinical and histopathological parameters were assessed with Chi-square test, Student's t test and Fisher's exact test. Potential risk factors for SLN metastasis were analysed by multivariate logistic regression models with the enter method, and odds ratios (OR) and $95 \%$ confidence intervals (CI) were calculated for categorical variables. The predictive value of the multivariate logistic regression model was measured with the 
Nagelkerke R Square method. The relationship between the reevaluated pT stage and the SNL status was assessed by Mann Whitney U test. $P$ values $<0.05$ were considered to be statistically significant and all $p$ values were two-sided. All statistical analyses were performed with the IBM SPSS Statistics Version 23.0 program.

\section{Results}

According to $\mathrm{AJCC} 7^{\text {th }} 152$ patients with $\mathrm{pT} 1 \mathrm{~b}$ melanoma entered our study. Among these 152 cases, 74 patients underwent only local wide excision with a $1 \mathrm{~cm}$ safety margin. In addition of local wide excision SLNB was also performed in 78 cases. Twelve patients were excluded for previous cutaneous or other malignancies; the remaining patients were not involved due to high biological age, severe comorbidities or pregnancy, or because they had simply declined the procedure. Lymphoscintigraphy successfully identified the draining lymphatic basin and sentinel node in all 78 patients. The majority of patients were sentinel node-negative $(n=69)$; in nine cases $(11.5 \%)$ metastasis was detected in the regional lymph nodes. The location, Clark level and mitotic rate of the tumour, the presence of ulceration, and regression were examined and compared. Complete lymph node dissection (CLND) was performed in 7/9 positive SLN cases. Additional metastatic LNs were found in two cases.

\section{Site of the Primary Tumour and SLN}

With regard to the location of the primary melanoma, the majority of these tumours were found on the lower extremities in women and on the trunk in men, as we expected (Table 1).

Among patients who underwent SLNB, the most frequent location of the primary tumours was the dorsal region of the trunk (27/78 overall, 14/34 in men and 13/44 in women); however, a high proportion of the tumours were located on the lower limbs in the women (16/44). In our series, the SLN positivity was independent of the location of the primary tumour (Fisher's exact test $p=0.9312$ ).

As regards the location of the sentinel nodes, 46 patients had axillary SLNB, in seven cases from both sides. Six of these
46 patients had metastatic lymph nodes. Three patients had sentinel nodes from both the axillary and inguinal regions; one of these patients had a positive sentinel node. In 22 cases, the nodes were removed from the inguinum ( 1 positive) and in the case of two patients from the popliteal region as well (1 positive). Four patients had sentinel nodes in the neck, and one patient had a sentinel node at an atypical site (over the scapula).

\section{Age and Gender}

The overall male/female ratio was 1:1. Of the patients who underwent SLNB, $43.5 \%$ were male, and the median age was 48.5 years (range $20-77 \mathrm{yrs}$ ). The onset of melanoma diagnosis did not differ significantly in the node-negative (48.8 yrs) and node-positive (46.3 yrs) groups. However, the mean age with pT1b/nodal involvement was 58.2 and 31.5 years among men and women, respectively. Moreover, in the younger age group ( $<35 \mathrm{yrs}$ ) the SLN positivity rate was $22.2 \%$, which is higher than the average in all cases. Demographic and histopathological characteristics of the SNLB group are shown in Table 2.

Multivariate logistic regression modelling demonstrates the association between SLN positivity and age, gender, Breslow, Clark level, and regression. The presence of regression in the primary tumour increases the probability of sentinel positivity by 5.796 -fold. There was a significant correlation noted between histological regression and sentinel lymph node positivity, however, no significant relation between the other characteristics examined (age, gender, Breslow, Clark level, mitosis index; Nagelkerke R square $=0.7$ ). After reassessing the $\mathrm{pT}$ stage according to the $\mathrm{AJCC}{ }^{\text {th }}$ guideline, 37 patients were reclassified from $\mathrm{pT} 1 \mathrm{~b}$ into $\mathrm{pT} 1 \mathrm{a}$ category. By repeating the statistical analyses there was no significant association between reclassified stage and SLN positivity indicating that regression may have independent prognostic value on the lymphatic spread of melanoma (Table 3).

\section{Discussion}

SNB has become standard procedure for the staging of the regional nodal basin in patients diagnosed with thin melanoma and remains one of the most important predictive factors of the

Table 1 Location of primary tumours among all patients and in the SLNB group

\begin{tabular}{lllll}
\hline Location & Overall male $(n=75)$ & Overall female $(n=77)$ & SLNB male $(n=34)$ & SLNB female $(n=44)$ \\
\hline Head and neck & 5 & 5 & 3 & 1 \\
Trunk ventral & 10 & 12 & 4 & 7 \\
Trunk dorsal & 33 & 21 & 14 & 13 \\
Upper extremity & 19 & 16 & 8 & 6 \\
Lower extremity & 7 & 22 & 4 & 16 \\
Acral & 1 & 1 & 1 & 1 \\
\hline
\end{tabular}


Table 2 Demographic and histological characteristics of the primary tumours with SLNB

\begin{tabular}{|c|c|c|c|c|c|}
\hline Variable & All patients with SLNB & SLN-positive & SLN-negative & $p$ value & OR \\
\hline Total no. & 78 & 9 & 69 & & \\
\hline Age mean (years) & 48.526 & 46.33 & 48.812 & $0.614^{\mathrm{b}}$ & \\
\hline$<35$ & 18 & 4 & 14 & $0.136^{\mathrm{a}}$ & \\
\hline $36-49$ & 21 & 0 & 21 & & \\
\hline $50-64$ & 32 & 4 & 28 & & \\
\hline$>65$ & 7 & 1 & 6 & & \\
\hline Gender & & & & $0.492^{\mathrm{a}}$ & $1.724(0.426-6.985)^{\mathrm{c}}$ \\
\hline Male & 34 & 5 & 29 & & \\
\hline Female & 44 & 4 & 40 & & \\
\hline \multicolumn{6}{|l|}{ Histological type } \\
\hline Superficial spreading & 72 & & & & \\
\hline Nodular & 4 & & & & \\
\hline Acral lentiginosus & 2 & & & & \\
\hline Location & & & & $0.9312^{\mathrm{a}}$ & \\
\hline Head and neck & 4 & 0 & 4 & & \\
\hline Trunk ventral & 11 & 2 & 9 & & \\
\hline Trunk dorsal & 27 & 4 & 23 & & \\
\hline Upper extremities & 14 & 1 & 13 & & \\
\hline Lower extremities & 20 & 2 & 18 & & \\
\hline Acral & 2 & 0 & 2 & & \\
\hline Thickness (mean) & 0.716 & 0.714 & 0.717 & $0.966^{\mathrm{b}}$ & \\
\hline Ulceration & & & & $0.586^{\mathrm{a}}$ & $0^{\mathrm{c}}$ \\
\hline Present & 8 & 0 & 8 & & \\
\hline Absent & 70 & 9 & 61 & & \\
\hline Mitotic rate (mean) & 2.25 & 1.89 & 2.29 & $0.494^{b}$ & \\
\hline Clark level & & & & $0.715^{\mathrm{a}}$ & $1.5(0.368-6.114)^{\mathrm{c}}$ \\
\hline II & 28 & 4 & 24 & & \\
\hline III & 50 & 5 & 45 & & \\
\hline Regression & & & & $0.044^{\mathrm{a}}$ & $4(0.916-17.459)^{\mathrm{c}}$ \\
\hline Present & 29 & 6 & 23 & & \\
\hline Absent & 49 & 3 & 46 & & \\
\hline Reclassified stage $\left(\mathrm{AJCC}^{\text {th }}\right)$ & & & & $0.566^{\mathrm{d}}$ & \\
\hline pT1a & 37 & 4 & 33 & & \\
\hline pT1b & 41 & $5^{\mathrm{e}}$ & 36 & & \\
\hline
\end{tabular}

${ }^{\text {a }}$ Fisher's exact test

${ }^{\mathrm{b}}$ Student t-test

${ }^{\mathrm{c}} \mathrm{OR}(95 \% \mathrm{CI})$

${ }^{\mathrm{d}}$ Mann Whitney U

${ }^{\mathrm{e}}$ Two patients had melanoma with Breslow $0.76 \mathrm{~mm}$, less than $0.8 \mathrm{~mm}$, but ordered into pT1b group

$\alpha=0.05$

$p$ two-sided

outcome for these patients [7-11]. However, Morton et al. reported that local complications occur in approximately $10 \%$ of SNBs, a percentage which is not higher than other elective, clean surgeries [14]. Several previous authors have attempted to identify predictive risk factors for nodal metastases in thin melanomas, including Breslow thickness, ulceration, regression, Clark level, age, and tumour-infiltrating lymphocytes to prevent overtreatment of these patients. However, no widely accepted consensus exists as to which patients are at risk for nodal metastases.

In our study, we aimed to assess how efficiently melanoma staging systems can predict the occurrence of nodal metastases 
Table 3 Multivariate logistic regression model of the clinicopathologic parameters

\begin{tabular}{lll}
\hline $\begin{array}{l}\text { Multivariate logistic } \\
\text { regression model }\end{array}$ & SLN positivity & \\
\hline Variable & OR $(95 \% \mathrm{CI})$ & $\mathrm{p}$ \\
Age & $.958(.916 ; 1.002)$ & 0.059 \\
Gender & $.651(.152 ; 2.782)$ & 0.562 \\
Breslow & $1.626(.036 ; 72.656)$ & 0.802 \\
Clark & $.560(.112 ; 2.807)$ & 0.480 \\
Mitosis index & $.723(.348 ; 1.502)$ & 0.385 \\
Regression & $5.796(1.046 ; 32.123)$ & $0.044 *$ \\
\hline
\end{tabular}

$O R$ odds ratio

CI confidence interval

$* p<0.05$ significant

method $=$ enter

in thin melanoma and whether there are any other additional criteria to improve this rate.

\section{Age and Gender}

Younger patient age is associated with a higher nodal metastasis rate among melanoma patients in general [3, 11, 15-18]; however, the available studies in thin melanoma are inconsistent on this factor, and there is no widely accepted specific age cut-off value under which SLNB should be performed. Kretschmer et al. reported that young patients ( $<40$ years) in a series of $0.75-1.00 \mathrm{~mm}$ thin melanoma patients had a significantly higher SLN positivity rate than older age groups [19]. Sondak et al. have also reported that relatively young age (besides MR and Breslow depth) is associated with positive SLNs in melanoma patients [16]. In our study, we did not apply a particular cut-off age for SLNB (range 20-77 years). We placed emphasis on the characteristics of the tumour rather than on comorbidities or biological age. Corresponding to findings by Balch et al., male patients were slightly older than female patients (49.5 vs. 47.7 yrs.) [20]. However, our study did not identify any significant difference with regard to age among the SLN-positive and -negative groups. On the other hand, a marked difference was observed between male and female patients with metastatic SLNs. The mean age of SLN-positive men was 58.2 years versus 31.5 years among women. This might be the result of the small sample size of patients involved, and further investigation may be required.

\section{Breslow Thickness}

The thickness of melanoma is generally considered the most useful prognostic factor in patients with thin melanoma. In a study of 121 thin melanoma cases, Hinz et al. [8] found that all SLN-positive patients belonged to the subgroup of tumour thickness range $0.9-0.99 \mathrm{~mm}$. Han et al. [21] reported that a Breslow thickness of $\geq 0.76 \mathrm{~mm}$ is associated with a 4.9 $12.8 \%$ rate of SLN metastases. However, according to these studies, only $0-2.3 \%$ of melanomas $<0.76 \mathrm{~mm}$ is associated with nodal disease. Our results are similar for thin melanomas $<1 \mathrm{~mm}(11.5 \%)$ but we have found a relatively high positive sentinel rate $(8 \%)$ for primary melanomas $<0.8 \mathrm{~mm}$. While Murali et al. [15] reported that patients with thin melanomas of $<0.50 \mathrm{~mm}$ have negative SLN stage, Bagaria et al. reported that melanomas of $<0.50 \mathrm{~mm}$ are identified as a factor of worse prognosis in term of SLN metastases [22]. In our series, $1 / 9$ cases of primary melanoma $<0.50 \mathrm{~mm}$ had nodal metastasis. Interestingly, corresponding to results by Mitteldorf et al. [9], we found no significant difference in sentinel nodal metastases between the $<0.76 \mathrm{~mm}$ and the $0.76-1.00 \mathrm{~mm}$ groups.

\section{Ulceration}

According to the latest two AJCC Melanoma Staging and Classification schemes, thin melanomas continue to be classified as T1b by the presence of ulceration [4, 13]. Several studies have reported that ulceration is a rare event $(1-15 \%)$ in thin melanomas [3, 23-25]. In our series, only 12 melanomas were ulcerated among the $152 \mathrm{pT} 1$ tumours (7.9\%). In the group of patients that underwent SNB, 8/78 primary tumours (10\%) showed ulceration. In their study of 147 thin melanoma patients, Yonick et al. found that ulceration (and Breslow thickness) was an independent predictor of nodal disease [26]. A study of 77 patients by Oliveira Filho et al. confirmed this result [27]. However, most studies have not shown ulceration as a significant predictor $[10,11,15,26,28-30]$. Kesmodel et al. reported that 181 thin melanoma patients with positive SLNs showed no signs of ulceration in the primary tumour [28]. Our results are consistent with these findings. None of the primary thin melanomas showing ulceration had nodal metastasis.

\section{Mitotic Rate}

Mitotic rate (MR) is defined as the maximum number of dermal mitoses per $\mathrm{mm}^{2}$. According to the staging system for melanomas in the $\mathrm{AJCC}^{\text {th }}$ edition, even a single mitosis can be categorized as T1b in the case of a small dermal tumour area, and, therefore, SLB should be considered [4, 31]. However, with only one mitotic figure being the cut-off point, this method may be unreliable even with an additional immunohistochemistry [32]. Several authors have reported that primary melanoma mitoses predict SLN status [10, 16, 28]. Furthermore, Sondak et al. have found young patients ( $<35$ years) that showed an MR correlation with a positive SLN. Interestingly, this was not the case with Breslow thickness [16]. Other studies showed no such association, even revealing that up to one-third of SLN- 
positive thin melanomas have zero mitosis $[3,15,33]$. In our study, there was no observable significance in mitotic rate between the node-positive and -negative group (Student $\mathrm{t}$-test; $\mathrm{t}=$ $-0.688 ; \mathrm{df}=76 ; p=0.494)$.

\section{Regression}

The clinical significance of clinical and histological regression in melanoma is still debated, with numerous studies reporting a higher rate of metastasis in thin, regressed melanomas [34, 35]. In our previous study [30], we also found that tumour regression predicts a higher risk of sentinel node involvement in melanomas $<2.0 \mathrm{~mm}$ in a series of 134 melanoma patients. Other authors showed no association with recurrence or survival $[18,36]$. This contradiction could be explained in part with the lack of a uniform definition for regression. Without these uniform criteria, the reproducibility of the results may be difficult. At our department, we used the criteria suggested by the Pathological Group of the World Health Organization
Melanoma Programme for the definition of regression. This includes the presence of a zone of tumour-free epidermis and dermis in which there is fibrosis, often along with inflammation and dilated vessels, flanked on one or both sides by a tumour (Fig. 1). These criteria for regression are also involved in the study by Botella-Estrada et al. [37] regarding (i) decrease or absence of melanoma cells in the dermal component of the tumour, presence of (ii) fibrosis, (iii) inflammatory infiltrate, (iv) melanophages, (v) neovascularization, (vi) epidermal flattening and (vii) keratinocytic/melanocytic damage. Features $(i-v)$ together are considered obligatory elements for the diagnosis of regression. The extension of regression was horizontally evaluated and divided into focal or main categories; the cut-off point was a percentage of $75 \%$ in the horizontal extension of primary melanoma.

In our recent study using univariate and multivariate logistic regression analysis, regression turned out to be the only significant independent predictor of SLN metastases (OR = 5.796). These results confirm our previous findings that

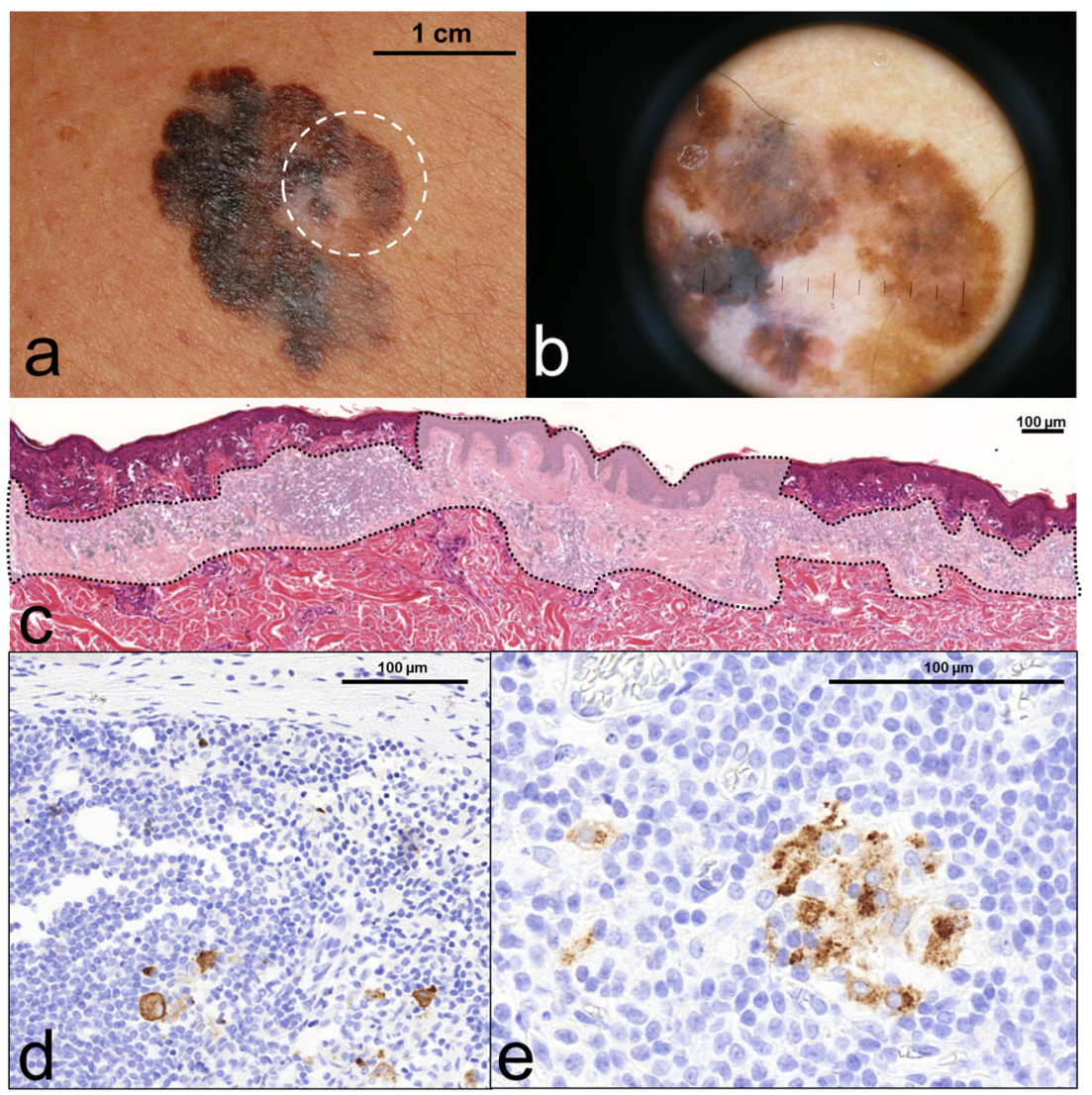

Fig. 1 shows a case report of a male patient aged 71, presenting regressing superficial spreading melanoma on his back region (a). At dermoscopy, the centre of the polychrome plaque displayed greyishwhitish area with peppering sign which is characteristic for regression (b). After the surgical removal of tumour, the histopathology showed extensive vanishing of junctional and dermal melanoma cells replaced by fibrosis, accumulation of melanophages and lymphocytic infiltrate together with focal neovascularisation (c - circumscribed faded area).
Only the edges of the presented section contained atypical residual microinvasive melanoma cells within the regressive microenvironment. Although calculated Breslow thickness from the residual melanoma counterpart showed only $0.532 \mathrm{~mm}$, dermal mitotic activity together with the adverse regression indicated SLNB. During the histopathological processing right axillary SLN contained scattered metastatic melanoma cells (d) which were also present in two other lymph nodes in the right axillary dissection sample (e) 
patients with Breslow $<2.0 \mathrm{~mm}$ but regressing melanomas have a four-time higher relative risk of developing nodal metastases than patients with non-regressing melanomas. This may verify our previous hypothesis that histological regression can result in a decreased Breslow thickness measurement and thus in some cases an erroneously more favourable prognostic estimate. In contrast, the overvaluation of early regression signs may also result in false regression data for statistical analyses.

\section{Conclusion}

According to the large, multicentre studies, thin melanomas $(<1.00 \mathrm{~mm})$ have a low, but significant risk for SLN metastases; however, these studies often apply various criteria for staging and performing SNB. Prospective standardized multicentre trials with standardized clinicopathologic and demographic criteria for performing SNB in thin melanomas are needed to specify widely accepted, reliable predictors.

Compared to the numerous multicentre-studies published recently, the benefit of our results may be the uniform criteria for diagnosis and treatment, as all the cases were managed at a single institution, with uniform surgical techniques and standard histology protocols for processing and evaluating primary melanomas and SLNs.

Our analysis support the recent $\mathrm{AJCC} 8^{\text {th }}$ classification that mitotic rate alone is not a sufficiently powerful predictor of SLN status in thin melanomas. If strict histopathological definition criteria are applied, regression might be an additional adverse feature that aids to identifying those T1 patients most likely to be SLN-positive, therefore sentinel lymph node biopsy might be considered in the case of patients with widely regressive thin $(<0.8 \mathrm{~mm})$ melanomas.

Acknowledgements The authors are grateful to the members of the Plastic Surgery, Dermatopathology and Oncodermatology Units of the Department of Dermatology and Allergology, University of Szeged for their contributions to the study.

Funding Information Open access funding provided by University of Szeged (SZTE). This research was supported by NKFI (OTKA) K-125509, GINOP_2.3.2-15-2016-00020 grant and Bolyai Scholarship Hungarian Academy of Science.

\section{Compliance with Ethical Standards}

Conflict of Interest The authors declare no conflict of interest.

Open Access This article is distributed under the terms of the Creative Commons Attribution 4.0 International License (http:// creativecommons.org/licenses/by/4.0/), which permits unrestricted use, distribution, and reproduction in any medium, provided you give appropriate credit to the original author(s) and the source, provide a link to the Creative Commons license, and indicate if changes were made.

\section{References}

1. Miller AJ, Mihm MC Jr (2006) Melanoma. N Engl J Med 355:5165

2. Siegel R, Naishadham D, Jemal A (2013) Cancer statistics, 2013. CA Cancer J Clin 63:11-30

3. Han D, Zager JS, Shyr Y, Chen H, Berry LD et al (2013) Clinicopathologic predictors of sentinel lymph node metastasis in thin melanoma. J Clin Oncol 31:4387-4393

4. Balch CM, Gershenwald JE, Soong SJ, Thompson JF, Atkins MB et al (2009) Final version of 2009 AJCC melanoma staging and classification. J Clin Oncol 27:6199-6206

5. Morton DL, Thompson JF, Cochran AJ, Mozzillo N, Nieweg OE et al (2014) Final trial report of sentinel-node biopsy versus nodal observation in melanoma. N Engl J Med 370:599-609

6. Sladden M, Zagarella S, Popescu C, Bigby M (2015) No survival benefit for patients with melanoma undergoing sentinel lymph node biopsy: critical appraisal of the multicenter selective lymphadenectomy trial-I final report. Br J Dermatol 172:566-571

7. Hieken TJ, Grotz TE, Comfere NI, Inselman JW, Habermann EB (2015) The effect of the AJCC 7th edition change in T1 melanoma substaging on national utilization and outcomes of sentinel lymph node biopsy for thin melanoma. Melanoma Res 25:157-163

8. Hinz T, Ahmadzadehfar H, Wierzbicki A, Holler T, Wenzel J et al (2012) Prognostic value of sentinel lymph node biopsy in 121 lowrisk melanomas (tumour thickness $<1.00 \mathrm{~mm}$ ) on the basis of a long-term follow-up. Eur J Nucl Med Mol Imaging 39:581-588

9. Mitteldorf C, Bertsch HP, Jung K, Thoms KM, Schon MP et al (2014) Sentinel node biopsy improves prognostic stratification in patients with thin (pT1) melanomas and an additional risk factor. Ann Surg Oncol 21:2252-2258

10. Ranieri JM, Wagner JD, Wenck S, Johnson CS, Coleman JJ III (2006) The prognostic importance of sentinel lymph node biopsy in thin melanoma. Ann Surg Oncol 13:927-932

11. Wright BE, Scheri RP, Ye X, Faries MB, Turner RR et al (2008) Importance of sentinel lymph node biopsy in patients with thin melanoma. Arch Surg 143:892-899

12. Joyce KM, McInerney NM, Joyce CW, Jones DM, Hussey AJ et al (2015) A review of sentinel lymph node biopsy for thin melanoma. Ir J Med Sci 184:119-123

13. Gershenwald JE, Scolyer RA, Hess KR, Sondak VK, Long GV et al (2017) Melanoma staging: evidence-based changes in the American Joint Committee on Cancer eighth edition cancer staging manual. CA Cancer J Clin 67:472-492

14. Morton DL, Cochran AJ, Thompson JF, Elashoff R, Essner R et al (2005) Sentinel node biopsy for early-stage melanoma: accuracy and morbidity in MSLT-I, an international multicenter trial. Ann Surg 242:302-311

15. Murali R, Haydu LE, Quinn MJ, Saw RP, Shannon K et al (2012) Sentinel lymph node biopsy in patients with thin primary cutaneous melanoma. Ann Surg 255:128-133

16. Sondak VK, Taylor JM, Sabel MS, Wang Y, Lowe L et al (2004) Mitotic rate and younger age are predictors of sentinel lymph node positivity: lessons learned from the generation of a probabilistic model. Ann Surg Oncol 11:247-258

17. Bleicher RJ, Essner R, Foshag LJ, Wanek LA, Morton DL (2003) Role of sentinel lymphadenectomy in thin invasive cutaneous melanomas. J Clin Oncol 21:1326-1331

18. Morris KT, Busam KJ, Bero S, Patel A, Brady MS (2008) Primary cutaneous melanoma with regression does not require a lower threshold for sentinel lymph node biopsy. Ann Surg Oncol 15: 316-322

19. Kretschmer L, Starz H, Thoms KM, Satzger I, Volker B et al (2011) Age as a key factor influencing metastasizing patterns and disease- 
specific survival after sentinel lymph node biopsy for cutaneous melanoma. Int J Cancer 129:1435-1442

20. Balch CM, Soong SJ, Gershenwald JE, Thompson JF, Coit DG et al (2013) Age as a prognostic factor in patients with localized melanoma and regional metastases. Ann Surg Oncol 20:3961-3968

21. Han D, Yu D, Zhao X, Marzban SS, Messina JL et al (2012) Sentinel node biopsy is indicated for thin melanomas $>/=0.76$ mm. Ann Surg Oncol 19:3335-3342

22. Bagaria SP, Ray PS, Joseph RW, Heckman MG, Rawal B et al (2013) Ultrathin primary is a marker for worse prognosis in lymph node-positive cutaneous melanoma. Cancer 119:1860-1867

23. Cecchi R, Buralli L, Innocenti S, De Gaudio C (2007) Sentinel lymph node biopsy in patients with thin melanomas. J Dermatol 34:512-515

24. Balch CM, Buzaid AC, Soong SJ, Atkins MB, Cascinelli N et al (2001) Final version of the American Joint Committee on Cancer staging system for cutaneous melanoma. J Clin Oncol 19:36353648

25. Rousseau DL Jr, Ross MI, Johnson MM, Prieto VG, Lee JE et al (2003) Revised American Joint Committee on Cancer staging criteria accurately predict sentinel lymph node positivity in clinically node-negative melanoma patients. Ann Surg Oncol 10:569-574

26. Yonick DV, Ballo RM, Kahn E, Dahiya M, Yao K et al (2011) Predictors of positive sentinel lymph node in thin melanoma. Am J Surg 201:324-327

27. Oliveira Filho RS, Ferreira LM, Biasi LJ, Enokihara MM, Paiva GR et al (2003) Vertical growth phase and positive sentinel node in thin melanoma. Braz J Med Biol Res 36:347-350

28. Kesmodel SB, Karakousis GC, Botbyl JD, Canter RJ, Lewis RT et al (2005) Mitotic rate as a predictor of sentinel lymph node positivity in patients with thin melanomas. Ann Surg Oncol 12: $449-458$
29. Wong SL, Brady MS, Busam KJ, Coit DG (2006) Results of sentinel lymph node biopsy in patients with thin melanoma. Ann Surg Oncol 13:302-309

30. Olah J, Gyulai R, Korom I, Varga E, Dobozy A (2003) Tumour regression predicts higher risk of sentinel node involvement in thin cutaneous melanomas. Br J Dermatol 149:662-663

31. Markovic SN, Erickson LA, Rao RD, Weenig RH, Pockaj BA et al (2007) Malignant melanoma in the 21st century, part 2: staging, prognosis, and treatment. Mayo Clin Proc 82:490-513

32. Abbas O, Miller DD, Bhawan J (2014) Cutaneous malignant melanoma: update on diagnostic and prognostic biomarkers. Am J Dermatopathol 36:363-379

33. Cooper C, Wayne JD, Damstetter EM, Martini M, Gordon J et al (2013) A 10-year, single-institution analysis of clinicopathologic features and sentinel lymph node biopsy in thin melanomas. J Am Acad Dermatol 69:693-699

34. Guitart J, Lowe L, Piepkorn M, Prieto VG, Rabkin MS et al (2002) Histological characteristics of metastasizing thin melanomas: a case-control study of 43 cases. Arch Dermatol 138:603-608

35. Blessing K, McLaren KM, McLean A, Davidson P (1990) Thin malignant melanomas (less than $1.5 \mathrm{~mm}$ ) with metastasis: a histological study and survival analysis. Histopathology 17:389-395

36. Brogelli L, Reali UM, Moretti S, Urso C (1992) The prognostic significance of histologic regression in cutaneous melanoma. Melanoma Res 2:87-91

37. Botella-Estrada R, Traves V, Requena C, Guillen-Barona C, Nagore E (2014) Correlation of histologic regression in primary melanoma with sentinel node status. JAMA Dermatol 150:828-835

Publisher's Note Springer Nature remains neutral with regard to jurisdictional claims in published maps and institutional affiliations. 